\title{
Organisation Justice Towards' Employees Voluntary Turnover: A Perspective of SMEs in Malaysia
}

\author{
Alvin Chong \\ Asia Pacific University of Technology and Innovation \\ Ibiwani Alisa Hussain \\ Asia Pacific University of Technology and Innovation \\ Noraini Ahmad \\ Asia Pacific University of Technology and Innovation \\ Jugindar Singh Kartar Singh \\ Asia Pacific University of Technology and Innovation
}

Received: Feb. 6, 2021 Accepted: Mar. 1, 2021 Online published: Mar. 26, 2021

doi:10.5296/ijhrs.v11i2.18459 URL: https://doi.org/10.5296/ijhrs.v11i2.18459

\begin{abstract}
Turnover of employees has gained the attention of organisations due to the impact of human resources on organisation performance and competitive advantage. This dilemma leads the management to struggle to find ways and retain employees. To attract, organisations use the "pull factors" to entice employees to perform better in the organisation. This study was conducted to investigate the relationship between the three dimensions of organisational justice: distributive, procedural and interactional justice towards voluntary turnover. This was an explanatory study that used a quantitative research design. Through a survey method, data was collected from a total of 115 respondents. The findings revealed that there was a significant relationship between employee turnover, distributive justice, procedural justice, and interactional justice. However, interactional justice had the strongest impact. This study also unearthed that attractive compensation is not the only method for the management to retain talent in organisations. Organisational justice plays an essential role in the retention of employees. These results will provide a better understanding of supervisors and human
\end{abstract}


resource professionals with additional insights into the impact of organisational justice on employees' turnover. This study indicates that organisations' interactional justice practised is considered a central factor for employee retention. Although prior research has investigated a number of these issues, this study was the first to focus on employees in Small and Medium Enterprises in Malaysia.

Keywords: organisational justice, interactional justice, procedural justice, voluntary turnover

\section{Introduction}

\subsection{Background}

Studies showed that 84 per cent of Malaysia's workers who are working in Small and Medium Enterprises (SMEs) were willing to leave their home country for an overseas job with no intention of migrating. In addition, 72 per cent of Malaysia's SMEs' workers have even intended to migrate to other countries and aim for a better career opportunity and lifestyle (Charpia, 2018). Approximately 38 per cent of SMEs face problems for filling the vacant job position with suitable candidates globally (Akunda et al., 2018). SMEs are common business companies established by the private sector. Several articles have proven that the employee who works in the company will have a high tendency to leave the company. The SMEs employer is facing problems for retaining talent in the company. The employees are thinking of working in another country instead of their own home country (Akunda et al., 2018). This issue is caused by the poor economic climate, high fluctuation of global oil price, and Ringgit Malaysia's devaluation (Shield \& Renee, 2018). However, these studies are mainly focusing on the overall performance of a particular country, leaving the treatment from the employers' end as an essential contributing factor to initiate the employees' intention to leave the company in the first place.

\subsection{Problem Statement}

Past research has shown that organisational justice perceptions by employees can significantly reduce turnover intention (e.g., Mengstie, 2020). The treatment of employees that includes organisational justice is essential towards retaining the. Perceived injustice can reduce the employee's motivation to accomplish their goals (Imani, 2009). Organisational justice can also impact the turnover of employees in an organisation (De Gieter, 2012). Higher turnover rates will result in higher costs and have an impact on the organisation's performance (Work Institute, 2019). According to previous reports, the turnover cost can be about one-half of an individual's overall annual compensation. (Keller and Cappeli, 2013). Furthermore, the cost of replacing an employee is substantial, with figures varying from $90 \%$ to $100 \%$ of the employee's annual salary. The high turnover rate of workers is one of the factors that lead to the failure of companies (Joshi \& Ratnesh, 2013). Employee turnover influences an organisation's success and profitability, and organisations must consider why workers intend to stay or quit. There are initiatives carried out to solve these problems, but not all management teams are willing to do so. Attempts such as training and development allow the workers to enhance themselves personally and professionally. Increase compensations and bonuses provide various benefit packages for the employees that cater to 
different needs for different workers. These are the aspects that the management focuses on, leaving organisational justice practices aside (Usmani, 2016). Despite the importance of organisational justice, most research on this matter is focused on large corporations and in developed countries. However, there a paucity of research that focussed on Small and Medium Enterprises in a developing country. Therefore, this study was conducted to investigate the influence of dimensions in organisational justice: distributive, procedural, and interactional justice towards employee voluntary turnover in SMEs in Malaysia.

\section{Literature Review}

\subsection{Employee Voluntary Turnover}

Employee voluntary turnover is defined as employees who leave his/her current organisation at his/her own will (George, 2017; Arif, 2018). The turnover could be the result of many situations such as a better offer for compensation (Sutanto, 2018), better career development opportunity (Arif, 2018), and other better fringe benefits offered from other organisation, and these led to a "push" factor and caused the employees to lose interest on staying in their current organisation. Following that, employees left the current organisation (Hao, 2016; Sutanto, 2018). Mistreatment, abusive, and an unfair working environment are also some of the determinants that pushed employees to voluntarily leave the organisation (Usmani, 2016; Arif, 2018). Therefore, this study was undertaken to investigate the three dimensions of organisational justice, namely distributive, procedural, and interactional justice towards employees' voluntary turnover.

\subsection{Organisational Justice and Turnover}

Distributive justice refers to fairness in allocating outcomes or rewards in the organisation (Ryan, 2016; Grondelle, 2018). Some of the outcomes that one employee expects might differ from another employee (Bennett et al., 2018). The distributor has a challenging task in determining the need for every employee, as it can satisfy and retain them (Hockett, 2019). In the work context, outcomes are a form of reward which includes wages, promotions, and career opportunities, while the inputs would include training, equipment and experience (Pepper, 2019). Managing distributive justice in an organisation is challenging for the manager (Hughes \& Merges, 2017; Grondelle, 2018; Hockett, 2019). They must provide equal work that comes with equal outcomes for the employees (Kappel 2018). The employees must be given equity to have equal opportunity to complete their work (Fronlich et al., 2018; Eleveld et al., 2020). The equity rule has been a benchmark for standardising the human resources policies such as salary distribution, approval of training and development opportunities, and eliminating favouritism behaviour in the organisation (Brinkmann, 2020). The manager has to consider a few factors during the distribution of rewards, such as their contribution and status. The employee's contribution to a particular task (Hassan \& Mojtaba, 2016; Frohlich et al., 2018; Edmundson, 2020) and the status of the employee are the key determinants for the compensation and rewards for the employee (Kappel, 2018; Pepper, 2019; Hockett, 2019). Many people missed when it comes to distributive justice because of the task's duration (Hancock et al., 2018). The duration of time has to be realistic and reasonable (Usmani, 2016; Arif, 2018). Investment in the employees, such as training and 
development, is considered vital for the organisation's employees (Hassan \& Mojtaba, 2016; Kappel, 2018). It is similar to instructions and demonstrations on handling a particular task (Grondelle, 2018; Pepper, 2019). A study done by Mueller and Price found that an intention to leave is formed when there is a sense of the unfair distribution of rewards and outcomes among employees (Hughes \& Merges, 2017; Hancock et al., 2018; Hussain \& Khan, 2019; Brinkmann, 2020).

H1: Organisational justice is related to employees' voluntary turnover.

\subsection{Procedural Justice and Turnover}

Procedural justice refers to the organisation's methods to make decisions and policies (Zhang et al., 2015; Tyler, 2017; Kim \& Beehr, 2020). Establishing a well-constructed policy is a challenging and time-consuming task for the management team (Bennett et al., 2018; Maiese et al., 2020). Inputs from the employees are significant for the management to consider when preparing the policies (Ryan, 2016; Tyler, 2017). It is essential to ensure that policies are compatible and tandem with the organisation's current set-up (Ryan, 2016; Tyler, 2017). Rules and regulations are made for fair treatment, and they must be applied to everyone in the organisation regardless of their status and years of service (Kim \& Beehr, 2020; Maiese et al., 2020). Fair policies help reduce favouritism in the organisation (Hancock et al., 2018; Bergami \& Morandin, 2019). Predetermined rules and regulations cannot be altered under any circumstances that could cause favouritism as it will violate procedural justice (Cropanzano, 2015; Ryan, 2016; Kim \& Beehr, 2020). Though honouring the policy is the outcome that the management is looking for, it could contradict the employees' perspectives (Gupta \& Singh, 2018). Employees' voice has to be heard before any justification was held upon them (Kurter, 2018; Ryan, 2018). Grievances from employees must be managed through the performance appraisal session (Ryan, 2016; Tyler, 2017). Good practice of procedural justice allows management to build a fair working environment that helps the organisation keeping key talents (Govindarajan, 2019; Ramdeo \& Singh, 2019).

H2: Procedural justice is related to employees' voluntary turnover.

\subsection{Interactional Justice and Turnover}

Interactional justice refers to the level of dignity and respect that is practised in the organisation about decisions and procedures (Usmani, 2016; Mullich, 2018). The outcome of interactional justice is where everyone in the organisation has to be treated with respect regardless of their personal and professional traits (Craig, 2017). A good practice of interactional justice should be shown not only from the treatment between superiors and subordinates, but rather everyone (Craig, 2017; Beheshti, 2019). This could motivate the employees to be loyal to the organisation, as they could work comfortably and respectfully in the organisation (Mullich, 2018; Dang \& Pham, 2020). Interactional justice is the best solution for counteracting procedural justice's rigidness by imposing humanity in the treatment of one to another (Beheshti, 2019; Prossack, 2020). The management could start practising interactional justice by becoming a role model for the subordinates (Craig, 2017; Eliasof, 2020; Dang \& Pham, 2020) and demonstrating the expected behaviours (Craig, 2017; 


\section{MInstitute Macrothink $_{\text {Int }}$}

International Journal of Human Resource Studies

ISSN 2162-3058 2021, Vol. 11, No. 2

Mullich, 2018; Dang \& Pham, 2020). This way, it will influence the subordinates to imply interactional justice as a norm in the organisation (Brownlee, 2019; Prossack, 2020). Good practice of interactional justice is also a great way to reduce issues such as sexual harassment (Spencer, 2020), disturbance from trade union (Winkler, 2018), misunderstanding or miscommunicating between staffs (Craig, 2017; Brownlee, 2019; Vigo, 2019), and most importantly high turnover rate (Usmani, 2016; Arif, 2018).

H3: Interactional justice is related to employees' voluntary turnover.

\section{Methodology}

\subsection{Research Design}

The study adopted a quantitative study, with primary data gathered using a survey questionnaire. The unit of analysis for the study was individual. There were 115 respondents who participated in the survey. The respondents were employees of SMEs in Malaysia. Survey questionnaires consist of 25 close-ended questions; the participants were informed about the confidentiality of the information they provided in the study, and their participation is on a voluntary basis. Items used in the survey questionnaire were adopted from Usmani (2016). A five-point Likert-scale was used in the study to measure all items in the survey questionnaire, and the measurement in the Likert-scale ranges from 1 (strongly disagree) to 5 (strongly agree). Data were gathered using an online survey platform using a google survey form. Distribution to the intended samples was conducted through convenience sampling and snowball sampling methods.

\subsection{Data Analysis}

Data Analysis was done by using the SPSS software. The questionnaires were checked for missing data. After editing, the data was created in the SPSS file. The demography information of respondents in this study was described. This study adopted several critical analysis methods such as descriptive analysis, frequency analysis, Pearson correlation and multiple regression analysis to describe the respondents. SPSS was used as a medium to analyse all data obtained from the respondents.

\section{Findings and Discussion}

\subsection{Participants Demographics}

The total number of respondents who participated in this study was 115 . There were five close-ended questions asked in the demography section. The study found 74 (64.3\%) female and $41(35.7 \%)$ male employees who participated in the survey based on the descriptive analysis. The majority of the participants were young employees and aged below 25 years old (63.5\%), followed by participants in the age group between 26-34 years old (29.6\%). On the educational level, $47 \%$ of the respondents obtained a bachelor's degree, while $49.7 \%$ obtained quite similar to a bachelor's degree. On working experience, most of the respondents $(44.3 \%)$ have working experience between 1-3 years, and income information revealed that most of the respondents received income in the range of below RM2000 (45.2\%).

\subsection{Descriptive Statistics}




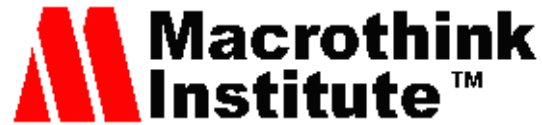

There were 20 items used in the survey questionnaire to measure all predictors and the dependent variable used in the study. For the distributive justice dimension, the item asked whether the respondents agreed that their current work schedule is fairly allocated for them, findings revealed with a score of 3.53. If the participants agreed that their pay is fairly distributed, on item asking, they received a score of 3.37. The participants are considered that their workload to be quite fair (mean rating $=3.39$ out of 5.00). Most of the participants thought that the given rewards in the workplace are fair (mean rating $=3.57$ out of 5.00). Participants in this study felt that their job responsibilities are quite fair (mean rating $=3.52$ out of 5.00).

\section{Procedural Justice}

The participants agreed that their supervisor's job decision was in a biased manner (mean rating $=3.21$ out of 5.00). The participants do think that it is essential that their concerns have to be heard before a job decision was made (mean rating $=3.33$ out of 5.00). They thought that the supervisor's consideration process towards the employees' justification, inputs, and thoughts was conducted thoroughly (mean rating $=3.48$ out of 5.00). The participants do think they received sufficient facilitation as they wanted to proceed with their requested task from their supervisor (mean rating $=3.52$ out of 5.00). The participants agreed on the regulations and treatment are applied to all employees regardless of other matter (mean rating $=3.46$ out of 5.00$)$.

\section{Interactional Justice}

The participants agree that they are treated with kindness and consideration in the workplace (mean rating $=3.50$ out of 5.00); they also agreed that they are treated with respect and dignity in the workplace (mean rating $=3.73$ out of 5.00 ). Their management is sensitive to the employees' personal needs (mean rating $=3.26$ out of 5.00 ) as their management has catered to different employees' needs. The participants think that the management decided honestly and sincerely on the employees' job (mean rating $=3.60$ out of 5.00). Their management has a proper etiquette when it comes to reasoning with the employees (mean rating $=3.59$ out of 5.00 ).

\section{Voluntary Turnover}

The majority of the SMEs' workers who took part in this study are satisfied with the current job (mean rating $=3.56$ out of 5.00). They also found that their opinions are respected at work (mean rating $=3.46$ out of 5.00). The participants think that their colleagues' overall satisfaction in the workplace is satisfied (mean rating $=3.28$ out of 5.00). The participants felt that the relationship between themselves and their superior was good (mean rating $=3.35$ out of 5.00). Lastly, the participants are satisfied with their superiors' management skills in handling employees' affairs (mean rating $=3.31$ out of 5.00).

\subsection{Reliability Testing}

Table 1 shows the reliability test of all the variables mentioned in this study. The highest Cronbach's Alpha value in this study is Voluntary Turnover with a value of 0.825 . All 
Cronbach's Alpha value in this study is in the range from 0.664 to 0.825 . This indicates that all of the study variables are reliable since they surpassed the acceptable threshold value of 0.6 .

Table 1. Reliability Test

\begin{tabular}{cccc}
\hline Number & Variables & Number of Items & Cronbach's Alpha \\
\hline 1 & Voluntary Turnover & 5 & 0.825 \\
2 & Distributive Justice & 5 & 0.754 \\
3 & Procedural Justice & 5 & 0.664 \\
4 & Interactional Justice & 5 & 0.754 \\
\hline
\end{tabular}

Table 2 explains the multiple regression analysis's significance based on its coefficients. According to Table 2, Distributive Justice $(\beta=0.311$, $p$-value $=0.000)$, Procedural Justice $(\beta$ $=0.215$, $\mathrm{p}$-value $=0.016)$, and Interactional Justice $(\beta=0.348, \mathrm{p}$-value $=0.000)$ has significant positive relationship with voluntary turnover, this indicates that the absence of organisational justices (independent variables) will lead employees to voluntary turnover. Table 2 also shows that Interactional Justice $(b=0.388)$ has the greatest contribution to the employees' voluntary turnover in this study.

\subsection{Hypothesis Testing}

Table 2. Coefficient Values Analysis

\begin{tabular}{lllll}
\hline & $\mathrm{b}$ & $\beta$ & $\mathrm{t}$ & $\mathrm{p}$-value \\
\hline (Constant) & $\mathbf{. 2 0 9}$ & & .162 & $\mathbf{. 8 7 1}$ \\
Distributive Justice & $\mathbf{. 3 3 7}$ & $\mathbf{. 3 1 1}$ & 3.961 & $\mathbf{. 0 0 0}$ \\
Procedural Justice & $\mathbf{. 2 4 2}$ & $\mathbf{. 2 1 5}$ & 2.439 & $\mathbf{. 0 1 6}$ \\
Interactional Justice & $\mathbf{. 3 8 8}$ & $\mathbf{. 3 4 8}$ & 4.120 & $\mathbf{. 0 0 0}$ \\
\hline
\end{tabular}

To identify the acceptance of this study's hypotheses, we will be focusing on the p-value; the hypothesis will be accepted when the p-value is less than 0.050 . Table 2 shows that all of the hypotheses were supported because the p-value of each variable is less than 0.05 . This finding implies that there was a significant relationship between distributive justice, procedural justice, and interactional justice towards employee turnover. The components mentioned in distributive justice, procedural justice, and interactional justice are crucial to retaining employees in SME-type organisations. In addition, employees are humans who tend to seek a better way of living rather than forcing themselves to work in an uncomfortable workplace.

The multiple regression analysis showed an R-square value of .527. This is the coefficient of determination. This analysis is to test the model fitness against predictors used towards the dependent variable. It was found that the $\mathrm{R}^{2}$ value is at 0.527 and indicated that all 
dimensions used in this study were able to explain $52.7 \%$ of turnover intention among employees at SMEs in Malaysia. However, the $\mathrm{R}^{2}$ indicated that more than half of the total percentage on the dependent variable used in this study, the remaining $47.3 \%$ are still subjected to other predictors that are either associated or not associated with the independent variables used in this study. Therefore, the absence of organisational justice is only one factor that leads SMEs' employees to leave the organisation voluntarily. There are still other factors that could lead to the exact outcome as well.

\section{Conclusion, Implications, Limitations and Recommendations}

\subsection{Conclusion}

This study discovered that attractive compensation is not the only method for the management to retain talent in the organisation. There are other aspects such as standard of protocol, application of rules and regulations, the relationship between superiors and subordinates that need to be covered to make employees feel comfortable staying in the organisation for a long time. In this study, all three forms of organisational justice, namely organisational justice, procedural justice, and interactional justice, had a significant and positive impact on employees' voluntary turnover. It was found that interactional justice had the strongest impact on the voluntary turnover of employees. Therefore, leaders and managers can play a vital role in retaining employees. This study showed that it is important to treat employees with dignity and respect. The employees who feel valued will have a lower intention to leave an organisation. Thus, the SMEs' management must treat organisational justice as a vital ingredient to retain talent in SMEs'.

\subsection{Implications}

There were several practical implications of this study. This study provided supervisors, line managers, and human resource managers in SMEs with additional insights relating to the impact of organisational justice on employees' turnover intention. The study highlighted the critical role of interactional justice. The results supported the notion that employees who are treated with politeness, dignity, and respect by superiors will feel valued and have a lower intention to leave organisations. Organisations need to have policies and procedures to retain talented resources to ensure the core competencies remain intact, leading to organisational success and competitive advantage. The higher-level organisational justice will encourage employees to stay longer and continue to contribute towards the organisation success. Organisation leaders need to understand and acknowledge that a healthy organisation needs to value employees and treat them with dignity and respect. There were also some contributions from theoretical and academic perspectives. This study also provides new and useful insights for academicians and researchers undertaking studies relating to organisational justice and retention of employees. This study highlighted the critical role of interactional justice. From a theoretical perspective, there are several contributions to this research. This research further added further knowledge to the existing body of knowledge. The findings are useful to academicians and future researchers. 


\subsection{Limitations and Recommendations for Future Research}

This study did have some limitations. To begin, the study only gathered information from current employees in SMEs. Interviews with workers who are leaving companies can produce better results and outcomes. In this situation, a qualitative analysis is recommended in order to collect accurate information from departing employees. It is also proposed that a mixed-method approach focused on explanatory sequential study design be used. Analysis of quantitative data accompanied by an analysis of qualitative data would offer a clearer understanding and interpretation of the results in this mixed-method approach. Another choice is to review the records from the exit interview with exiting employees. The exit interview can provide valuable insights into the real problems in the organisation that lead to turnover of employees.

\section{References}

Akunda, D., Chen, Z., \& Gikiri, S. (2018). Role of HRM in Talent Retention with Evidence. Journal Management and Strategy, 9(2), 8-19. https://doi.org/10.5430/jms.v9n2p8

Arif, S. (2018). Impact of Organizational Justice on Turnover Intentions: Moderating role of Job Embeddedness. Seisense. Journal of Management, 1(2), 35-52. https://doi.org/10.33215/sjom.v1i2.16

Beheshti, N. (2019). 10 timely statistic about the connection between employee engagement and wellness. Forbes. https://www.forbes.com/sites/nazbeheshti/2019/01/16/10-timely-statistics-about-the-connecti on-between-employee-engagement-and-wellness/\#16f6ba8722a0

Bennett, S., Hine, L., \& Mazerolle, L. (2018). Procedural Justice. https://doi.org/10.1093/obo/9780195396607-0241

Bergami, M., \& Morandin, G. (2019). Relationship between perceived justice and identification: The mediating role of organisational images. Employee Relations, 41(1), 176-192. https://doi.org/10.1108/ER-09-2017-0210

Brinkmann, J. (2020). Health Disparities: Thoughts on distributive justice. The O\&P Edge. https://opedge.com/Articles/ViewArticle/2020-06-01/health-disparities-thoughts-on-distributi ve-justice

Brownlee, D. (2019). 4 employee engagement trends that leaders need to know. Forbes. https://www.forbes.com/sites/danabrownlee/2019/08/18/4-employee-engagement-trends-thatleaders-need-to-know/\#1e3b218a33f7

Cappelli, P., \& Keller, J. R. (2013). Classifying work in the new economy. Academy of Management Review, 38(4), 575-596. https://doi.org/10.5465/amr.2011.0302

Charpia, J. (2018) Employee Turnover Intentions in the Construction Industry: A Quantitative Correlational Study. (Unpublished Thesis). Diss. Northcentral University.

Craig, W. (2017). Why a strong employee/employer relationship is important? Forbes. 
https://www.forbes.com/sites/williamcraig/2017/09/20/why-a-strong-employeeemployer-relat ionship-is-important/\#6ad6989f64d9

Cropanzano, R., Fortin, M., \& Kirk, J. F. (2015). How do We Know When We are Treated Fairly? Justice Rules and Fairness Judgments, Research in Personnel and Human Resources Management. Research in Personnel and Human Resources Management, Emerald Group Publishing Limited, 33, 279-350. https://doi.org/10.1108/S0742-730120150000033010

Dang, T., \& Pham, A. (2020). What make banks' front-line staff more customer-oriented? The role of interactional justice. International Journal of Bank Marketing, 38(4), 777-798. https://doi.org/10.1108/IJBM-09-2019-0321

De Gieter, S., De Cooman, R., Hofmans, J., Pepermans, R., \& Jegers, M. (2012). Pay-level satisfaction and psychological reward satisfaction as mediators of the organisational justice-turnover intention relationship. International studies of management \& organisation, 42(1), 50-67. https://doi.org/10.2753/IMO0020-8825420103

Eleveld, A., Kampen, T., \& Arts, J. (2020). Welfare to work and social justice: an introduction to an interdisciplinary normative perspective on welfare policies. In A. Eleveld, T. Kampen, \& J. Arts (Eds.), Welfare to work in contemporary European welfare states: Legal, sociological and philosophical perspectives on justice and domination (pp. 1-24). Policy Press. https://doi.org/10.1332/policypress/9781447340010.003.0001

Eliasof, M. (2020). Grow Your Business by Investing in Your People Skills. Forbes. https://www.forbes.com/sites/forbesbusinesscouncil/2020/03/10/grow-your-business-by-inves ting-in-your-people-skills/\#182c387348bf

Frohlich, N., Oppenheimer, J., \& Eavey, C. (2018). Choices of Principles of Distributive Justice in Experimental Groups. Midwest Political Science Association, 31(3), 606-636. https://doi.org/10.2307/2111285

George, J., \& Wallio, S. (2017). Organisational justice and millennial turnover in public accounting. Employee Relations, 39(1), 112-126. https://doi.org/10.1108/ER-11-2015-0208

Govindaraju, N. (2019). The effect of Organisational justice on employee turnover with the mediating role of Job embeddedness. Research Scholar, Segi University, Malaysia, 5(2), 254-263.

Grondelle, V. (2018). A Pragmatic Approach of Distributive Justice. (Unpublished Thesis). University Pompeu Fabra.

Gupta, A., \& Singh, V. (2018). Influence of organisational justice on intention to stay of IT professionals. International Journal of Indian Culture and Business Management, 17(4), 428. https://doi.org/10.1504/IJICBM.2018.095677

Hancock, B., Hioe, E., \& Schaninger, B. (2018). The fairness factor in performance management.

McKinsey. https://www.mckinsey.com/business-functions/organization/our-insights/the-fairness-factor-in -performance-management 


\section{Macrothink}

International Journal of Human Resource Studies

ISSN 2162-3058

2021, Vol. 11, No. 2

Hao, Y., Hao, J., \& Wang, X. (2016). The relationship between organisational justice and job satisfaction: Evidence from China. Journal of Chinese Human Resource Management, 7(2), 115-128. https://doi.org/10.1108/JCHRM-07-2016-0012

Hassan, K., \& Mojtaba, B. (2016). Distributive Justice and the Fundamental Human Rights (Focusing on Rights to Healthy Environment). Journal of Politics and Law, 9(7), 43-56. https://doi.org/10.5539/jpl.v9n4p43

Hockett, R. (2019). Our Money's Not Green Enough. Forbes. https://www.forbes.com/sites/rhockett/2019/11/12/our-moneys-not-green-enough/\#2b735c70 6823

Hughes, J., \& Merges, R. (2017). Copyright and Distributive Justice. Notre Dame Law Review, 92(2), 513-577.

Hussain, M., \& Khan, M. S. (2019). Organisational justice and turnover intentions: probing the Pakistani print media sector. Evidence-based HRM, 7(2), 180-197. https://doi.org/10.1108/EBHRM-04-2018-0030

Imani, J. (2009). Analysing the simple and multiple relationship of organisational justice with job satisfaction among the teachers of exceptional schools in Bandar Abas city. J Educ Sci Univ Tabriz, 2(51), 27-34.

Joshi, A., \& Ratnesh, K. (2013). Human resource budgeting and HRM strategies: A paradigm shift that increases job satisfaction, effectiveness of recruitment decisions of human assets. International Journal of Management Research and Reviews, 3(1), 2327-2337.

Kappel, M. (2018). How to pay employees the right way (because you can't afford to pay them the wrong way). Forbes. https://www.forbes.com/sites/mikekappel/2018/11/26/how-to-pay-employees-the-right-way-b ecause-you-cant-afford-to-pay-them-the-wrong-way/\#a3e9176bcdcd

Kim, M., \& Beehr, T. A. (2020). Making the case for procedural justice: employees thrive and work hard. Journal of Managerial Psychology, 35(2), 100-114. https://doi.org/10.1108/JMP-03-2019-0154

Kurter, H. (2018). The 4 outdated workplace rules employers still grip onto. Forbes. https://www.forbes.com/sites/heidilynnekurter/2018/11/19/the-4-outdated-workplace-rules-e mployers-still-grip-onto/\#488268e1122e

Maiese, M., Burgess, H., \& Cast, S. (2020). Procedural Justice. Beyond Intractability. https://www.beyondintractability.org/essay/procedural_justice

Mengstie, M. M. (2020). Perceived organisational justice and turnover intention among hospital healthcare workers. BMC psychology, 8(1), 1-11. https://doi.org/10.1186/s40359-020-0387-8

Mullich, J. (2018) How to close the gap between employer and employee expectations. Forbes. 
https://www.forbes.com/sites/adp/2018/03/27/how-to-close-the-gap-between-employer-and-e mployee-expectations/\#3f16c64c20cf

Pepper, A. (2019). The Right Approach to Executive Pay. https://www.forbes.com/sites/londonschoolofeconomics/2019/06/06/the-right-approach-to-ex ecutive-pay/\#3d54174f6c65

Prossack, A. (2020). 3 ways to boost employee engagement. Forbes. https://www.forbes.com/sites/ashiraprossack1/2020/02/28/3-ways-to-boost-employee-engage ment/\#260af4f43054

Ramdeo, S., \& Singh, R. (2019). Abusive supervision, co-worker abuse and work outcomes: procedural justice as a mediator. Evidence-based HRM, 7(3), 325-341. https://doi.org/10.1108/EBHRM-09-2018-0060

Ryan, L. (2018). Ten company rules that are unfair to employees. Forbes. https://www.forbes.com/sites/lizryan/2016/09/27/five-workplace-rules-to-follow-and-five-tobreak/\#383240bc4746

Shields, R. (2018). The Role of Perceived Organisational Support and the impact of its constructs on Teacher Retention. (Unpublished Dissertation), University of Pretoria.

Spencer, E. (2020). Study finds women at the top experience more sexual harassment. https://www.forbes.com/sites/erinspencer1/2020/01/16/study-finds-that-women-at-the-top-ex perience-more-sexual-harassment/?sh $=421544 \mathrm{~b} 975 \mathrm{~d} 9$

Sutanto, E., Sampson, J., \& Mulyono. (2018). Organisational Justice, Work Environment and Motivation. International Journal of Business and Society, 19(2), 313-322.

Tyler, T. (2017). Procedural Justice and Policing: A Rush to Judgement? Annual Review of Law and Social Science, 29-53. https://doi.org/10.1146/annurev-lawsocsci-110316-113318

Usmani, S. (2016). Impact of Distributive Justice, Procedural Justice, Interactional Justice, Temporal Justice, Spatial Justice on Job Satisfaction of Banking Employees. Integrative Business and Economics, 2(1), 351-382

Vigo, J. (2019). Is Human Contact Being Eliminated from Our Communications Today? Forbes.https://www.forbes.com/sites/julianvigo/2019/11/22/is-human-contact-being-eliminate d-from-our-communications-today/\#104259d954cd

Winkler, M. (2018). Sexual harassment at work: what the law says. Forbes.https://www.forbes.com/sites/hecparis/2018/10/22/sexual-harassment-at-work-what-th e-law-says/\#7789b97e23c7

Work Institute (2019). Retention Report. https://info.workinstitute.com/hubfs/2019\%20Retention\%20Report/Work\%20Institute\%2020 19\%20Retention\%20Report\%20final-1.pdf

Zhang, Y., Long, L., \& Zhang, J. (2015). Pay for performance and employee creativity: The 


\section{Macrothink}

International Journal of Human Resource Studies

ISSN 2162-3058 2021, Vol. 11, No. 2

importance of procedural justice and willingness to take risks. Management Decision, 53(7), 1378-1397. https://doi.org/10.1108/MD-11-2013-0596

\section{Copyright Disclaimer}

Copyright for this article is retained by the author(s), with first publication rights granted to the journal.

This is an open-access article distributed under the terms and conditions of the Creative Commons Attribution license (http://creativecommons.org/licenses/by/4.0/). 